\title{
A Novel CAT > GAT (H 3311R) Missense Mutation in Exon 30 of the PKD1 Gene in a Patient Affected With Autosomal Dominant Polycystic Kidney
}

\author{
Atousa Hafizi ${ }^{1}$; Saeid Reza Khatami ${ }^{1}$; Hamid Galehdari ${ }^{1}$; Gholam Reza Shariati ${ }^{2,{ }^{*}}$; Ali \\ Hossein Saberi ${ }^{3}$; Mohamad Hamid ${ }^{4}$ \\ ${ }^{1}$ Department of Genetic, Faculty of Sciences, Shahid Chamran University of Ahvaz, Ahvaz, IR Iran \\ ${ }^{2}$ Narges Medical Genetics and PND Laboratory, Ahvaz, IR Iran \\ 3 Department of Medical Genetics, Ahvaz Jundishapur University of Medical Sciences, Ahvaz, IR Iran \\ ${ }^{4}$ Department of Molecular Medicine, Biotechnology Research Center, Pasteur Institute of Iran, Tehran, IR Iran \\ *Corresponding author: Gholam Reza Shariati, Narges Medical Genetics and PND Laboratory, Ahvaz, IR Iran. E-mail: shariatig@yahoo.com
}

Received: January 26, 2014; Accepted: March 15, 2014

\begin{abstract}
Introduction: Autosomal dominant polycystic kidney disease (ADPKD) is one of the most common genetic kidney disorders. Genetic studies have demonstrated an important allelic variability among patients but very few data are known about the genetic variation in Iranian populations.

Case Presentation: In this study, in order to verify the ADPKD in a patient with some clinical symptoms and study the variations of the PKD1 gene for the first time in Iranian population, the PKD1 gene was entirely sequenced. Coding exons analysis of PKD1 by exon direct sequencing was performed. Molecular genetic testing found a novel mutation in the patient.

Conclusions: It was a missense mutation CAT > GAT at position 3311 in exon 30 of PKD1. CAT > GAT causes the conversion of amino acids histidine to argenine and change the transmembrane domain and proper function of the polycystin 1 protein.
\end{abstract}

Keywords: Autosomal-Dominant Polycystic Kidney Disease (ADPKD); Novel Mutation; Polycystic Kidney Disease 1(PKD1)

\section{Introduction}

Autosomal dominant polycystic kidney disease (ADPKD; OMIM ID:173900) is a monogenic multi-systemic disorder characterized by the development of renal cysts and various extra-renal manifestations. It is the most common inherited renal disease with a prevalence of approximately 1 in 400 to 1 in 1000 live births in all races [1]. This disease accounts for more than $10 \%$ of all cases of end-stage renal diseases (ESRD) [2]. ADPKD is characterized by numerous enlarged fluid-filled epithelial cysts typically in both kidneys and in some cases in other organs. Now 2 causal genes, PKD1 (MIM 601313) and PKD2 (MIM 173910), have been identified for ADPKD that are located respectively on chromosome 16 (16p13.3, 46 exons) and chromosome 4 (4q21, 15 exons) [3]. The PKD1 gene mutated in $85 \%$ of all ADPKD cases. Polycystin-1 is a receptor protein for cellcell/matrix interactions which plays crucial roles in the regulation of cell proliferation and apoptosis [4]. In the present study, we report a case of novel mutation discovered from the direct mutation screening of all exons in the PKD1 gene in one Iranian patient with ADPKD.

\section{Case Presentation}

The patient was a 15-year-old boy, the only child of consanguineous parents. There was no history of ADPKD in this family. On sonography of the abdomen of the patient, the liver was normal in size, but contained multiple simple cysts, the largest was $27 \times 27 \times 25 \mathrm{~mm}$ located in the right lobe. On sonography of the kidneys and bladder, both kidneys were normal in position and however enlarged in size. Ten milliliter of peripheral blood was collected in EDTA containing tube. DNA was extracted by the standard salting out protocol. PKD1 gene-specific PCR primers were synthesized for all exons (a list of the primers used is available on request). The primers for exon 30 amplification was F: 5'-CCATGTTCCCTGGGTCTCT-3' and R: 5'-GCTGCTCTCTCAACAAGAGGA-3' The PCR was conducted under the following conditions: 100 ng genomic DNA, $200 \mu \mathrm{M}$ deoxyribonucleotide triphosphates (dNTPs), 1.5 $\mathrm{mm} \mathrm{MgCl}, 2.5$ units supertaq polymerase, and $25 \mathrm{pmol}$ each primer. Amplification was carried out in $25 \mu \mathrm{L}$ volumes and 35 cycles: $93^{\circ} \mathrm{C}$ for $1 \mathrm{~min}, 60^{\circ} \mathrm{C}$ for 30 seconds and $72^{\circ} \mathrm{C}$ for 45 seconds. Direct sequencing of the exons was performed using the big dye terminator cycle sequencing ready reaction kit (Applied Biosystems) on an ABI Prism 3700 automated genetic analyzer (Applied Biosystems). The same PCR primers were used for sequencing reactions. Finally, the sequences were compared to the reported gene sequence using the BLASTN program.

Direct sequencing analysis of the patient, after compari-

Copyright (C) 2015, Zahedan University of Medical Sciences. This is an open-access article distributed under the terms of the Creative Commons Attribution-NonCommercial 4.0 International License (http://creativecommons.org/licenses/by-nc/4.0/) which permits copy and redistribute the material just in noncommercial usages, provided the original work is properly cited. 
son with PKD1 reference sequence, demonstrated a sporadic heterozygous missense mutation CAT $>$ GAT substitution in exon 30 of the PKD1 gene in the patient, which causes an amino acid exchange of histidine to argenine (Figure 1).

\section{Discussion}

PKD1 gene mutations are considered as an important factor causing ADPKD. In $85-90 \%$ of patients mutations concern PKD1 gene and PKD2 in 10-15\% of cases [5]. A large number of methods have been used to screen for mutations in ADPKD for research and clinical aims, but direct sequencing is still considered the method of choice [6]. We therefore performed systematic screening of the coding region of the PKD1 gene by PCR-direct sequencing method. The present study is the first description of the PKD1 variant in ADPKD patients living in Iran. We analyzed an affected person with polycystic kidney deficiency with PCR and direct sequencing of coding exons of the PKD1 gene. As a result we identified a genetic variant of PKD1 in ADPKD patient. It was a missense mutation CAT > GAT (H 3311R) located in the exon 30 of the PKD1 gene, that changed histidine to argenine in the transmembrane domain of the polycystin1 protein (Figure 2).
Polycystins are proteins that have been found to play important roles in cell to cell and cell to extracellular matrix interactions. Research into the function of these proteins has also revealed that they play a part in cilia action in the nephrons and calcium channeling [7].

Hydropathy plot and computer-assisted analyses identified 9 to 11 transmembrane regions from amino acid 3075 to 4104 with intervening intracellular and extracellular loops [8]. Our found mutation changes the transmembrane domain and disturbs the polycystin1 proper function. Nevertheless, it is a first step to future multicenter studies for better description of genetic variants in Iranian ADPKD patients.

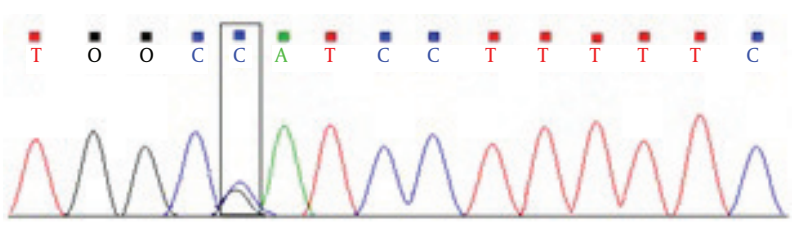

Figure 1. The Result of Genetic Sequencing, Showing the Heterozygous Missense Mutation CAT > GAT in Exon 30 of the Patient's PKD1 Gene (Sequencing With Forward Primer)

Figure 2. A, Structure of Normal Transmembrane Domain of the Polycystin-1 Protein; B, the H 3311R Mutant Transmembrane Domain of the Polycystin-1 Protein

A

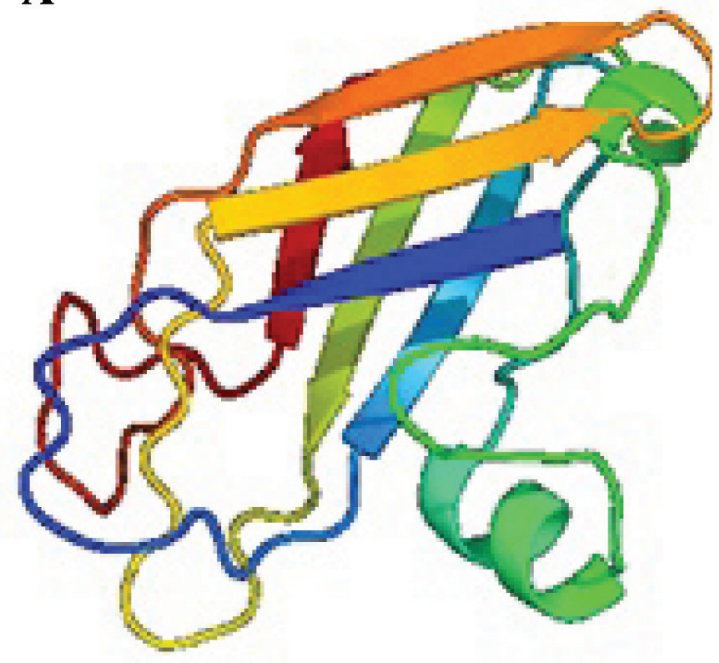

B

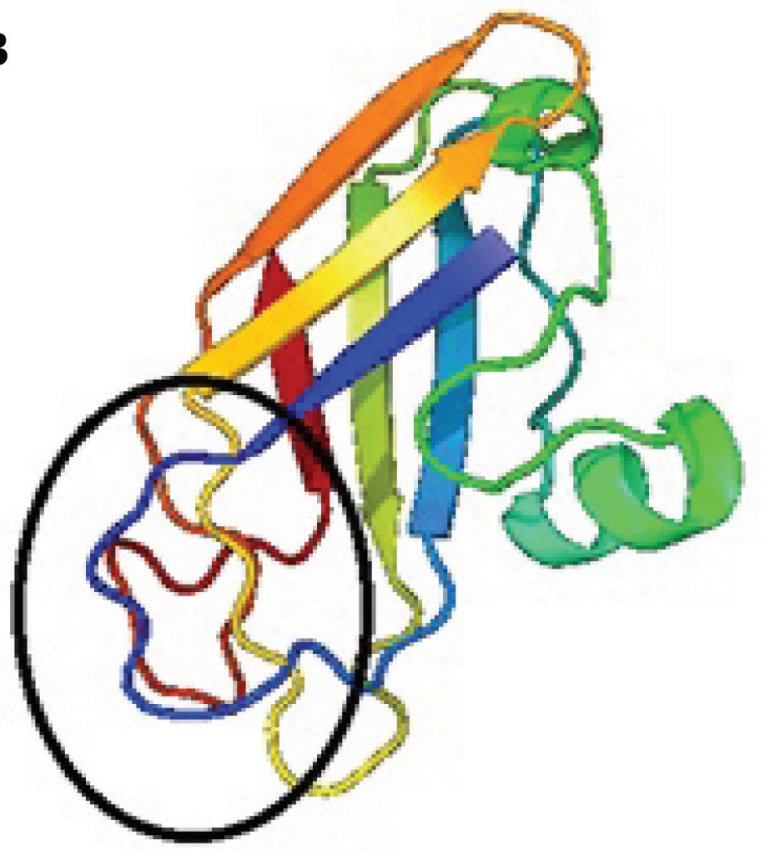

The differences between two protein structures have shown with black circles. Pictures prepared by Phyre2 software. 


\section{Acknowledgements}

The authors wish to thank the Narges Genetic Laboratory staff and all members of the ADPKD family for their cooperation. This study was supported in part by grant No.636410 of Shahid Chamran University.

\section{Authors' Contributions}

All authors had equal role in design, work, statistical analysis and manuscript writing.

\section{Funding/Support}

This study was supported in part by grant No.636410 of Shahid Chamran University.

\section{References}

1. Qi XP, Du ZF, Ma JM, Chen XL, Zhang Q, Fei J, et al. Genetic diagno- sis of autosomal dominant polycystic kidney disease by targeted capture and next-generation sequencing: utility and limitations. Gene. 2013;516(1):93-100.

2. Tan YC, Blumenfeld J, Rennert H. Autosomal dominant polycystic kidney disease: genetics, mutations and microRNAs. Biochim Biophys Acta. 2011;1812(10):1202-12.

3. Mochizuki T, Wu G, Hayashi T, Xenophontos SL, Veldhuisen B, Saris JJ, et al. PKD2, a gene for polycystic kidney disease that encodes an integral membrane protein. Science. 1996;272(5266):1339-42.

4. Goilav B. Apoptosis in polycystic kidney disease. Biochim Biophys Acta. 2011;1812(10):1272-80.

5. Torres VE, Harris PC, Pirson Y. Autosomal dominant polycystic kidney disease. Lancet. 2007;369(9569):1287-301.

6. Hoefele J, Mayer K, Scholz M, Klein HG. Novel PKD1 and PKD2 mutations in autosomal dominant polycystic kidney disease (ADPKD). Nephrol Dial Transplant. 2011;26(7):2181-8.

7. Gallagher AR, Hidaka S, Gretz N, Witzgall R. Molecular basis of autosomal-dominant polycystic kidney disease. Cell Mol Life Sci. 2002;59(4):682-93.

8. No authors listed. Polycystic kidney disease: the complete structure of the PKD1 gene and its protein. The International Polycystic Kidney Disease Consortium. Cell.1995;81(2):289-98. 